be stored in the deposit library? (3) Some of the public libraries and other smaller institutions have rarities which they cannot preserve properly or which they must house in buildings that are not fireproof. Again it might be desirable to obtain state funds for the proper preservation of such material in a unit of the deposit library specially constructed to take care of a limited number of rare books. With the wholesale destruction of cultural objects in Europe, increased responsibility falls on the shoulders of Americans to see that rare and valuable material in libraries here is properly preserved. Here is one means by which rarities could be safeguarded for smaller institutions and yet be made available to them for use when needed.

\section{References}

Massachusetts. Laws, Statutes, etc. "An Act to Incorporate New England Deposit Library and Regulating the Operation of Said Library and Authorizing Certain Libraries to Make Use of Its Facilities." (In Massachusetts. General Court. Acts and Resolves, 194I, chapter 240.)

Metcalf, Keyes D. "The New England Deposit Library." Library Quarterly I2:622-28, July 1942.

Osborn, Andrew D. "Books for the Deposit Library." Harvard University Library Notes 4:80-83, March 1942.

Work, R. L. "New England Deposit Library." Library Journal 67:358, April I942.

By. HAROLD L. LEUPP

\title{
Storage of Little-Used Library Materials
}

$M r$. Leupp is librarian of the University of California Library, Berkeley.

$\mathrm{D}$ ESPITE theoretical objections to division of the collections, in the cold light of financial and other practical considerations the storage method of dealing with accumulations of little-used materials in a large library certainly has its points. The principal difficulties involved, no one of which seems necessarily insurmountable, appear to be about as follows:

(I) Difficulty of selecting material to be stored
To comb out the collections title by title would be a formidable undertaking. Records of use would not help much, since the unrecorded use of certain materials is extensive and important. Very large libraries probably will include considerable groups of little-used material, transfer of which to storage would be not only a relatively simple matter but would release a maximum of shelf space with slight expenditure of time and labor. But even Harvard, with its four million volumes, according to my information, plans to store only three hundred thousand, or 
about $7 \frac{1}{2}$ per cent of them. In a working library of smaller size, say of less than a million and a half volumes, there are less likely to be large groups of material which might be separated from the main collection with reasonable assurance that they would be needed only infrequently. For such a library to select for storage enough books appreciably to ease congestion in the stacks would be, by the combing-out process, a slow, laborious, and costly process. The University of California Library, for instance, would have to select something like thirty-five thousand volumes to provide shelf space for the accretions of a single year.

\section{(2) Changing catalog and other records}

In transferring groups of material from one of the university's libraries to another, we have found alteration of the records the most troublesome and costly feature of the undertaking. Generally accepted library procedure seems to have enmeshed books in such a web of records that it has become almost as costly to relocate a book, or to discard it, as to secure and process it in the first place. Librarians would do well to restudy this situation, to eliminate all records not absolutely essential to library operation as presently conducted, and to try to simplify those which remain. In addition, the sacredness of close classification involving long and complicated call numbers might well be subjected to scrutiny. Both matters have a direct bearing upon the cost and difficulty of transfer to storage: the complications they entail render it doubtful whether the relief afforded by storage of thousands of individual books would justify the cost. With procedure less elaborate and more elastic, transfer of books to storage might be made a relatively simple matter. It would be much less difficult to correct initial errors in choice of material to be stored, permitting a more sweeping approach to the problem of selection.

\section{(3) Cost of maintenance}

The New England Deposit Library program seems well adapted to conditions such as those which obtain in the Boston area and in other metropolitan areas such as those centering in New York or Chicago. Its essence is cooperation of neighboring libraries of large size, each contributing to the cost and each depositing a considerable body of material. I doubt if the plan is equally well adapted to libraries not located in or near library centers. Unless the cooperating libraries are of somewhat similar character and at least approach equality in size or value of content, most of the expense and all of the grief would fall to the share of the dominant institution, which also would be the one least likely to benefit from the materials stored by the other collaborators. If this view is correct, the most immediate question for the dominant library to determine is whether cooperative storage is the most economical and otherwise satisfactory way of avoiding, or more probably of postponing, congestion of its own stacks. Generally, I think the answer would be "No." If that is so, there remains the question whether the dominant library's contribution of little-used material to the common pool would render this material more accessible to other collaborators. An affirmative answer would raise the further question of whether this result could not be reached, without the machinery and expense, by simple modification of the loan regulations of the dominant library.

Whether it is storage or something else, a solution must be found to the problem 
of stack congestion which faces most libraries and all university libraries. Public library systems serving a municipality, or a wider area such as a county, have an answer in multiplication of distributing agencies. This solution is not open to the reference library or, except to a very limited extent, to the college or university library. For the university library not yet confined within the rigid walls of an architectural monument, the solution seems to lie in a main building functional in character so located and planned that it can be extended indefinitely. For a university library already embalmed in a monumental building, a partial solution lies in limited decentralization; this, however, will merely postpone the day of reckoning.

Libraries which do not find the cooperative storage plan su.ted to their conditions (and I think this will be true of a large majority of university and college libraries) should and probably will exp'ore the possibilities of storage of their leastused materials off campus or on campus in a building more simply constructed and less desirably located than the main library building. Such a storehouse may be planned for storage solely or for storage and occasional reader use. The first will provide maximum storage capacity with minimum requirements: freedom from dampness and excessive sunlight or extremes of temperature on the negative side, and on the positive, shelving, a table or two, one or more booktrucks, a book lift if the books are housed on more than one level, adequate if modest artificial lighting, and messenger service. The second will involve, in addition to the foregoing, heat and ventilation, toilet facilities, telephone connection with the main library, reader accommodations, more artificial light, pos- sibly a rudimentary catalog, and attendants. The second plan will be more costly but will insure less frequent recalls of stored books to the main library. On this point the experiences of Iowa State College Library and Ohio State University Library, as set forth in the minutes of the December I940 meeting of the Association of Research Libraries, are illuminating:

Mr. Brown spoke of the warehouse recently constructed on the Iowa State College campus at a cost per volume considerably lower than the proposed Boston building. $\mathrm{He}$ stated that seventy thousand volumes, approximately one fifth of his collection, had been sent there and that these had been carefully selected, but that the circulation was averaging fifty volumes per day. Mr. Manchester, who has about the same number of volumes stored at Ohio State, reported a similar experience.

At the University of California a special committee has been studying the library problem of the Berkeley campus for more than two years. Among the suggestions considered by the committee is one which involves construction of a building of rather simple type for a lower division library. A separate lower division library would relieve the pressure on reading room space in the main building but alone would not materially ease congestion in the stacks. It should be feasible to so plan the building as to provide a considerable storage area within its walls. Probably this would cost more than off-campus storage but certainly much less than enlargement of the main building, and the necessary juxtaposition of the two buildings would insure the considerable advantage of housing the stored books in close proximity to the main collection. Little equipment would be required other than shelving, while operating cost would be negligible. 